National Marine

Fisheries Service

Fishery Bulletin

Spencer F. Baird

NOAA

Abstract-An unusually strong year class of goosefish (Lophius americanus) was first observed in the spring of 2015, and the length mode for this particular cohort remained evident for several years. We collected monthly samples from within this length mode over a period of 3 years and considered them fish with known ages for validating ages estimated by using illicia and vertebrae. Recent research had found vertebral ages for goosefish to be inaccurate, and a method in which illicia are used for Lophius species in Europe seemed promising. However, ring counts from illicia matched the known age only $50 \%$ of the time and were not replicable (9\% agreement). Ring counts from vertebrae never matched the known age but were replicable in $68 \%$ of samples. Marginal increment analysis of illicia from fish that matched the known age provided evidence that one annulus is formed on the illicium in spring or summer of each year for fish aged from 1 to 2 years. Because of the low accuracy of age estimates made with both illicia and vertebrae, as well as the high bias of aging with vertebrae, we concluded that the methods based on these structures did not provide useful age estimates of goosefish. The observed growth rate, based on the progression of the length mode during our study, was much faster than the growth rates based on vertebral ages.

Manuscript submitted 27 May 2021. Manuscript accepted 23 November 2021. Fish. Bull. 120:13-25 (2021).

Online publication date: 29 December 2021. doi: 10.7755/FB.120.1.2

The views and opinions expressed or implied in this article are those of the author (or authors) and do not necessarily reflect the position of the National Marine Fisheries Service, NOAA.

\title{
Validation of methods for aging goosefish (Lophius americanus) based on length-mode progression of a strong cohort
}

\author{
Sandra J. Sutherland (contact author) \\ R. Anne Richards \\ Email address for contact author: sandy.sutherland@noaa.gov \\ Northeast Fisheries Science Center \\ National Marine Fisheries Service, NOAA \\ 166 Water Street \\ Woods Hole, Massachusetts 02543
}

The goosefish (Lophius americanus) is one of the most economically important fish species of the continental shelf off the northeastern United States. This species has been managed conservatively because of major uncertainties in stock assessment (NDPSWG, 2007; Haring and Maguire, 2008). One of the most significant uncertainties is the growth curve, which has been viewed with caution (NDPSWG, 2007) because it appears linear rather than asymptotic (Richards et al., 2008).

The growth curve for goosefish is based on ages derived from vertebrae, with an aging method that was used at the NOAA Northeast Fisheries Science Center (NEFSC) during 1998-2007. Age estimation efforts at the NEFSC were suspended in 2007, because of concerns raised at a stock assessment review (NDPSWG, 2007). The structures normally used to estimate ages for other fish species (e.g., scales and sagittal otoliths) cannot be used for goosefish because they lack scales and because sagittal otoliths are not reliable structures for aging this species (Armstrong et al., 1992; Hartley, 1995).

The vertebral method was described by Armstrong et al. (1992), who examined marginal increment widths on vertebrae and concluded that rings were formed in May of each year. Results from Armstrong et al. (1992) indicate that vertebrae met the minimal criteria for use as an aging structure (Van Oosten, 1928). However, direct validation of the vertebral aging method had not been undertaken, perhaps because goosefish have very poor survival in captivity (Richards et al., 2011). Recently, Bank et al. (2020) successfully completed a direct age validation study that involved chemical marking of wild and laboratory-maintained goosefish. They demonstrated that the vertebral aging method was accurate less than $50 \%$ of the time for fish up to 2.4 years after tagging. However, results of their preliminary examination indicate that use of illicia (first spines on the dorsal fin) might provide more reliable age estimates. Illicia are the primary structures used to age white anglerfish (L. piscatorius) and black anglerfish (L. budegassa) in Europe (Duarte et al. ; Fariña et al., 2008; Landa et al., 2013).

An opportunity for further age validation work was presented by an exceptionally strong recruitment event

\footnotetext{
${ }^{1}$ Duarte, R., J. Landa, I. Quincoces, H. Dupouy, E. Bilbao, J. Dimeet, A. Marçal, H. McCormick, and G. Ni Chonchuir. 2002. Anglerfish ageing guide, $40 \mathrm{p}$. Working document of the 4th international ageing workshop on European anglerfish; Lisbon, 14-18 January. [Available from website.]
} 
for goosefish that occurred along the Atlantic coast of the United States in 2015. Recruitment indices in June 2015 were nearly an order of magnitude higher than long-term averages (Richards, 2016), with a modal length encompassing the size at settlement (Able et al., 2007). This clearly defined length mode remained evident for several years, providing a natural tag for identifying samples with known ages.

We collected samples from the 2015 year class of goosefish at ages of 1-3 years as the foundation for an age validation study focused on examining both illicia and vertebrae. Our goals were 1) to confirm year-class membership of our samples, 2) to determine if ages estimated from illicia and vertebrae were accurate, 3) to evaluate the precision of age estimates from the use of these structures, and 4) to determine the timing of annulus formation on illicia. In addition, we estimated growth rates for fish 1-3 years old.

\section{Materials and methods}

\section{Length composition from surveys}

Goosefish were captured and measured during annual fishery-independent surveys conducted by the NEFSC along the Atlantic coast of the United States from Virginia to Georges Bank (Fig. 1). These surveys included the NEFSC bottom trawl surveys (Stauffer, 2004), conducted in spring and autumn, and the NEFSC and Virginia Institute of Marine Sciences scallop dredge survey (NEFSC, 2010), conducted each June.

The length distribution of goosefish in surveys between June 2015 (when the strong year class was first observed in catches) through September 2018 was examined. At each survey time step, length at age was estimated by fitting normal curves to the dominant length mode (stratified mean number per tow at length) presumed to represent the

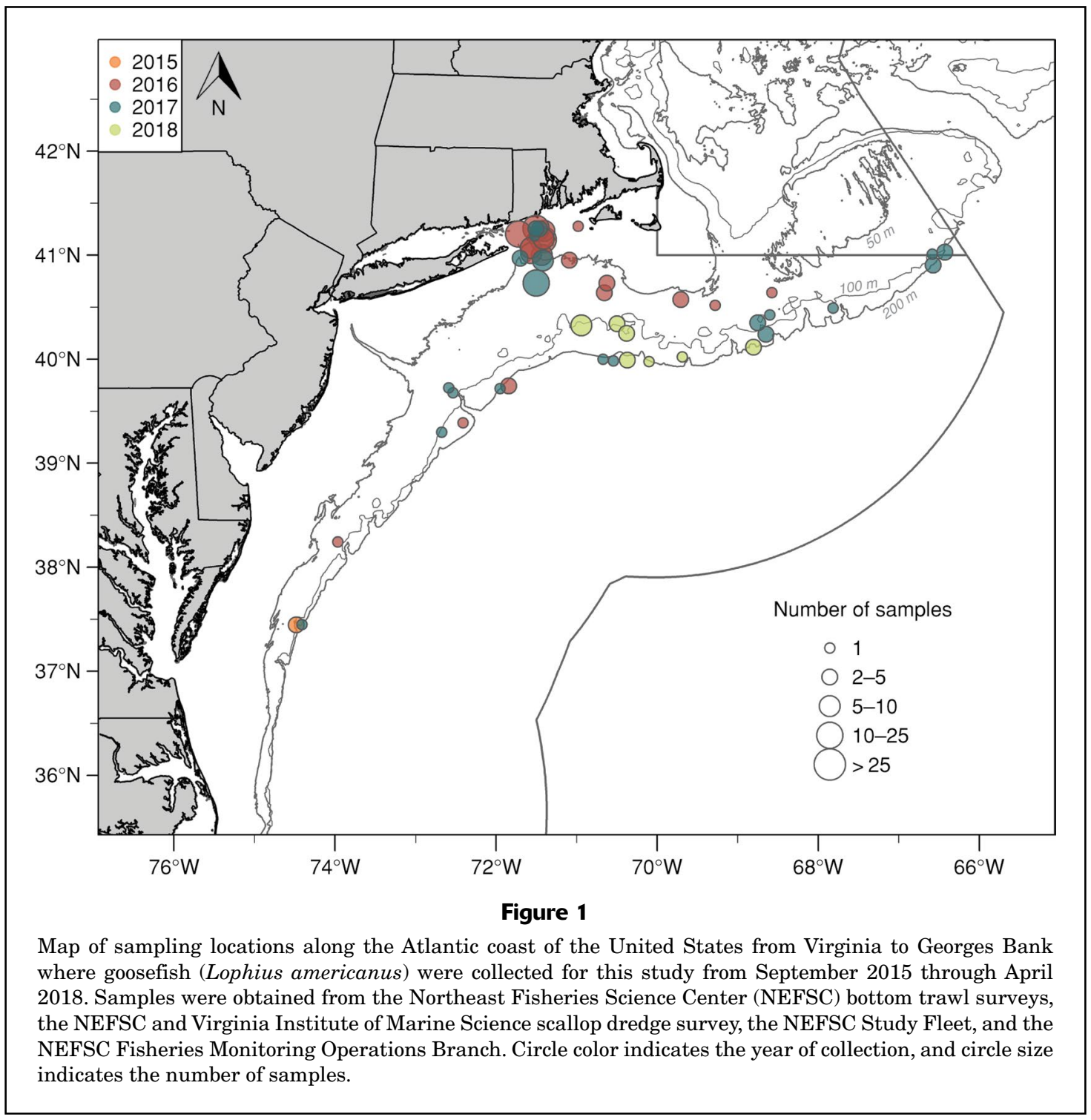


2015 year class. Normal parameters were estimated by using NORMSEP software, a program for analyzing a mixture of normal distributions (Pauly et al., 1986; Gayanilo et al., 2005). The size estimates of the length mode for each month were later used to select samples from within the mode for the validation study.

\section{Sample collection}

Samples of the 2015 year class (with determination of year class based on fish length, as described here previously) were obtained from the Atlantic coast of the United States from Virginia to Georges Bank (Fig. 1). Sampling occurred during the NEFSC bottom trawl surveys in 2016-2018 (spring survey) and 2015-2016 (autumn survey) and during the NEFSC and Virginia Institute of Marine Sciences scallop dredge survey in June 2016. To obtain samples in months when no surveys occurred, additional samples were obtained through the NEFSC Study Fleet program (Palmer et al., 2007) and the NEFSC Fisheries Monitoring Operations Branch (NEFSC ${ }^{2}$ ). The overall sampling effort spanned from September 2015 through April 2018, although monthly sampling was limited to the period from May 2016 through July 2017.

All fish were frozen whole and shipped to the laboratory for dissection. Each fish was measured (in total length [TL] in centimeters), weighed (in grams), and examined macroscopically to determine sex. The illicium and a segment of the vertebral column were removed.

\section{Hatch date}

In order to verify year-class membership of fish in the strong length mode, we additionally removed the lapillar otoliths from 2 presumed young-of-the-year goosefish from within this length mode by using methods described in Landa et al. ${ }^{3}$ These fish were fortuitously collected on 4 September 2015, before our dedicated sampling began.

The lapillar otoliths were prepared for daily aging following methods described in Secor et al. (1991) and Wright et al. (2002). Each otolith was mounted in epoxy, sectioned along the sagittal plane, manually ground (240- and 600grit sandpaper) to reveal the primordium, and polished.

Images of the lapillar otolith sections were taken at $125 \times$ magnification with an Olympus ${ }^{4}$ BX60 microscope, Olympus DP70 camera, and imaging software cellSens, vers. 1.11 (Olympus Corp., Tokyo, Japan). One age reader used the images to count the rings (Fig. 2) from

\footnotetext{
${ }^{2}$ NEFSC (Northeast Fisheries Science Center). 2016. Observer operations manual, 163 p. Northeast Fish. Sci. Cent., Natl. Mar. Fish. Serv., Woods Hole, MA. [Available from website.]

${ }^{3}$ Landa, J., A. Antolínez, J. Barrado, J. Fontenla, C. Hernández, B. Villamor, C. Dueñas, and M. R. Navarro. 2014. Age determination procedures for benthic fish in Spanish Institute of Oceanography (IEO), 34 p. Int. Doc., Inst. Esp. Oceanogr., Santander, Spain. [Available from website.]

${ }^{4}$ Mention of trade names or commercial companies is for identification purposes only and does not imply endorsement by the National Marine Fisheries Service, NOAA.
}

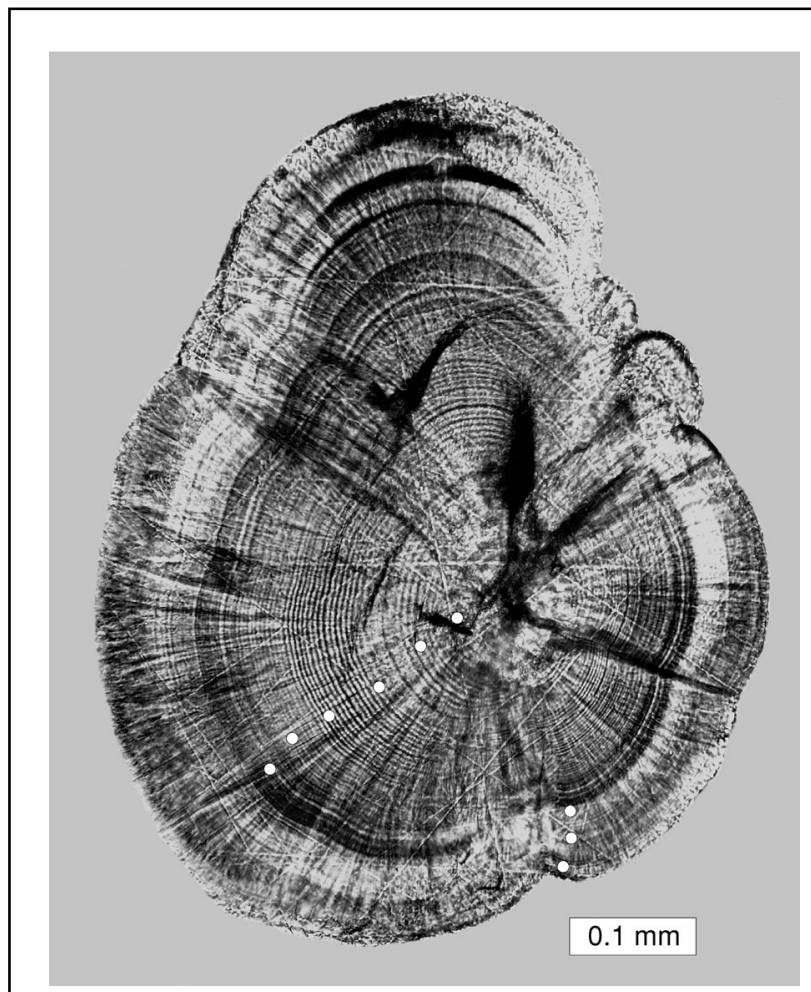

Figure 2

Photograph of a sectioned and ground lapillar otolith of a 14-cm-TL goosefish (Lophius americanus) captured on the outer shelf off the coast of Virginia on 4 September 2015. The estimated hatch date is 4 June 2015. The white dots indicate every tenth ring.

the primordium to the outer edge, with replicate counts on 3 successive days (this reader trained with $\mathrm{D}$. Secor, of the University of Maryland Center for Environmental Science, Solomons, MD, to learn methods for processing and reading samples for daily aging). It was assumed that the first ring was formed at hatching and that each ring represented $1 \mathrm{~d}$ of growth (Hislop et al., 2001; Hernández et al., 2015). Provided that the 3 readings were within $10 \%$ of each other, the average of the 3 counts was used to calculate hatch date (the collection date minus the number of rings).

\section{Age estimation}

Illicia were prepared according to methods described in Duarte et al. ${ }^{1}$ Each illicium was skinned and cleaned, marked $0.5 \mathrm{~cm}$ above the top of the basal bulb, and allowed to dry. The illicia were then mounted in polyester resin, with 10-15 samples per row, and sectioned at the mark on a highspeed saw with a diamond-impregnated blade (LabCut 250, Benetec Ltd., Rugby, UK) to a thickness of $0.5 \mathrm{~mm}$.

Vertebrae were processed according to methods established by Armstrong et al. (1992) but were not sectioned. The eighth vertebra was excised from the spinal column, cleaned of tissue, and baked at $230^{\circ} \mathrm{C}$ in an oven until dried and darkened (20-60 min). 


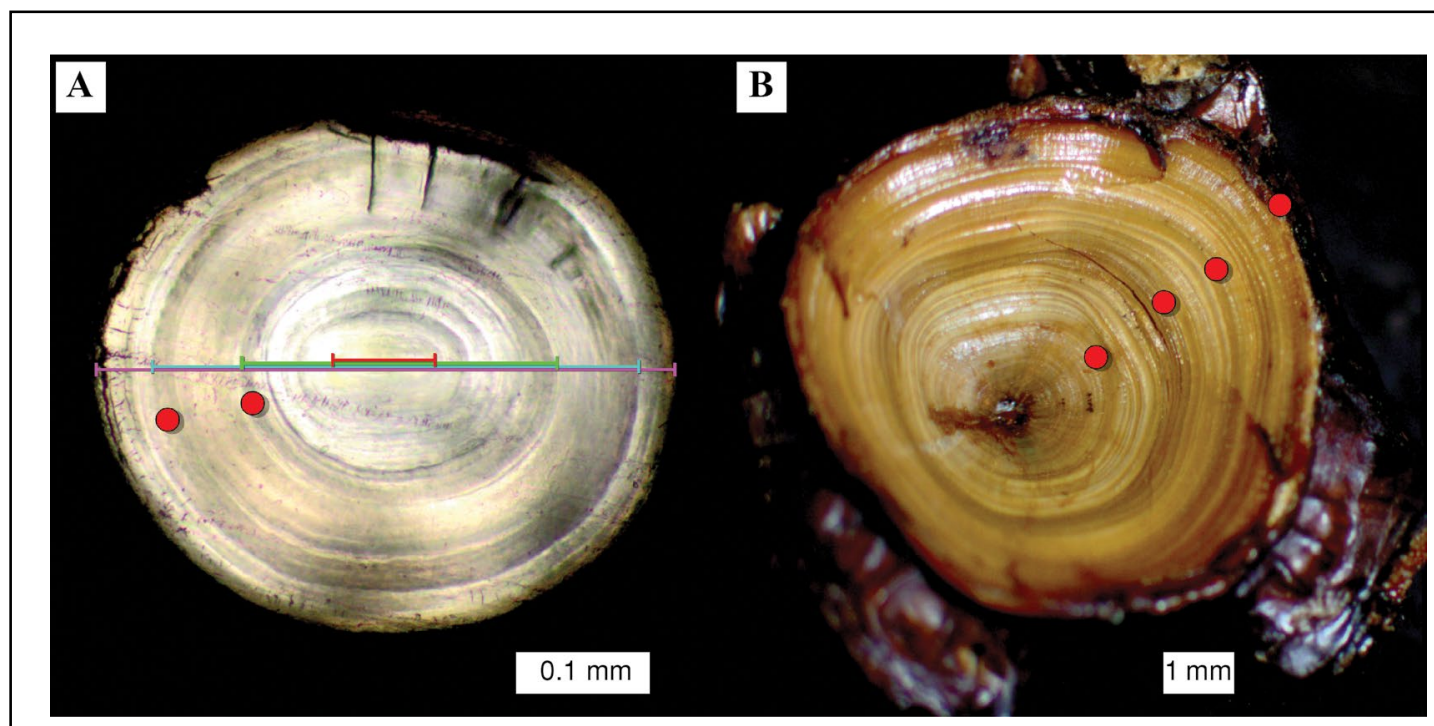

Figure 3

Annotated images of age structures, $(\mathbf{A})$ an illicium section and $(\mathbf{B})$ a baked vertebra, taken from a 41-cm-TL goosefish (Lophius americanus) with a known age of 2 years that was captured on 9 April 2017 south of Rhode Island. Each ring is marked with a red dot. The image of the illicium section shows 2 rings and the following measured diameters: settling check (red), first ring (green), last ring (blue), and total (pink). The image of the vertebra shows 4 rings.

Rings on each structure were counted twice following NEFSC aging protocols (Penttila and Dery, 1988) by one age reader, with at least 2 weeks between readings. Data on month, but not year, of capture were available to the age reader. Any samples for which the 2 ring counts differed were reexamined later; samples for which the count still could not be resolved were excluded from the analysis.

The reading order of rows of illicia (10-15 samples per row) was randomized before samples were examined. Vertebral samples were viewed in a haphazard order, by mixing together the envelopes that held the samples and viewing the samples in the order they were pulled out of a box.

The reader had over 15 years of experience with age reading methods, including the vertebral method for aging goosefish. However, the reader had examined fewer than 200 illicia prior to this study. Immediately before examining the study samples, the reader reviewed a set of 24 images of illicia from goosefish that had been examined and annotated by another age reader $\left(\mathrm{Landa}^{5}\right)$ experienced with illicia from anglerfish sampled in Europe.

Sectioned illicia (Fig. 3A) were immersed in a 1:1 solution of glycerin and 70\% isopropyl alcohol and were viewed with transmitted light at 40× magnification on an Olympus BH2 compound microscope (Olympus Corp.). Recommended practices for viewing illicia of white anglerfish (Duarte et al. ; Landa et al., 2013) were followed, including adjusting lighting and focus, counting the dark rings, and using axes with greater color contrast. It was assumed that the

\footnotetext{
${ }^{5}$ Landa, J. 2016. Personal commun. Cent. Oceanogr. Santander, Inst. Esp. Oceanogr., Promontorio San Martín s/n, 39004 Santander, Cantabria, Spain.
}

first ring would be nearly circular and that it would be outside both an oval settling check and a false annulus (as has been observed in white anglerfish by Wright et al., 2002). This process yielded first rings comparable in diameter to those in the annotated images.

Vertebrae (Fig. 3B) were interpreted following the methods of Armstrong et al. (1992). Samples were viewed with reflected light at $10 \times$ magnification on a dissecting microscope (Leica MZ6, Leica Camera AG, Wetzlar, Germany).

After both structures from all fish had been assigned a final ring count, accuracy of readings (ring counts versus known ages) for each structure was calculated across all fish. Known ages were based on the calendar year of capture (i.e., a fish captured in 2016 had a known age of 1 year). Later, test counts were made on a random subset of samples for each structure, allowing intra-reader precision (test counts versus ring counts) to be estimated.

Statistics calculated for each of these measures were percent agreement and the mean coefficient of variation (CV) (Chang, 1982). For both precision tests, a Bowker's test of symmetry (Bowker, 1948; Hoenig et al., 1995) was additionally applied to test for bias in the paired ring counts (one count each from the initial and the test count for a given structure of a sampled fish). At the NEFSC aging laboratory, $80 \%$ is considered an acceptable level of agreement; an acceptable $\mathrm{CV}$ is under $5 \%\left(\mathrm{NEFSC}^{6}\right)$.

\footnotetext{
${ }^{6}$ NEFSC (Northeast Fisheries Science Center). n.d. Quality assurance and quality control estimates for the production ageing of northwest Atlantic species: statistical measures. [Available from website, accessed November 2021.]
} 


\section{Marginal increment analysis}

Marginal increment analysis was conducted only for illicia because it had been done previously for vertebrae (Armstrong et al., 1992). Samples were limited to those collected during May 2016-May 2017 and for which the ring count matched the known age. Furthermore, only samples that had at least one band inside the edge (i.e., a minimum age of $1+$; the notation $1+$ indicates the presence of additional material outside the first ring) were included because relative increment width cannot be calculated on younger fish, whose illicia lack rings inside the edge.

Illicia were imaged and measured with knowledge of known age but without knowledge of fish length or capture date. The order in which they were examined was randomized by row. Images were taken at $150 \times$ magnification with an Olympus $\mathrm{BH} 2$ microscope, an Olympus DP25 camera (Olympus Corp.), and 64-bit TWAIN Twacker software (vers. 2.0; TWG, 2008). ImageJ software (vers. 1.49v; Schneider et al., 2012) and the ObjectJ plugin (vers. 1.03s; University of Amsterdam, available from website) were used for image processing.

Diameters of the settlement check, first ring, last ring inside the edge $\left(R_{\mathrm{n}}\right)$, and total illicium diameter $(D)$ were measured to the nearest $0.0001 \mathrm{~mm}$ along the axis with the largest settlement check diameter (Fig. 3A). Relationships between these measurements (settlement check, first ring, and total diameter) and total length were examined by using linear regression on untransformed data with the regression analysis add-in for
Microsoft Excel 2016 (Microsoft Corp., Redmond, WA). Regression results were used to test the assumption that the diameters of the settling check and first annulus were constant across the range of fish lengths. Total illicium diameter was expected to increase linearly with fish length.

These measurements were then used to calculate the relative marginal increment (MIR) (Sun et al., 2002):

$$
M I R=\frac{D-R_{\mathrm{n}}}{R_{\mathrm{n}}-R_{\mathrm{n}-1}},
$$

where $R_{\mathrm{n}-1}=$ the penultimate ring.

If the last ring is on the edge, $D-R_{\mathrm{n}}=0$. For fish with only one ring inside the edge (i.e., fish with estimated ages of $1+$ or 2 years), $R_{\mathrm{n}-1}$ is not present, simplifying the calculation to the following equation (Vilizzi and Walker, 1999):

$$
M I R=\frac{D-R_{\mathrm{n}}}{R_{\mathrm{n}}} .
$$

Average MIR was calculated for each month, and minima in the monthly MIR values were considered indicative of the timing of ring deposition.

\section{Results}

\section{Survey length composition and sample collection}

The length mode representing the 2015 year class (Table 1, Fig. 4) was first seen in the scallop dredge

\section{Table 1}

Known age, mean length with standard deviation (SD), and growth increment of the dominant length mode of goosefish (Lophius americanus) collected during surveys conducted by the NOAA Northeast Fisheries Science Center from June 2015 through September 2018 along the Atlantic coast of the United States from Virginia to Georges Bank. Mean length was estimated by using normal curves fit to the stratified mean number per tow at length. Growth increment was calculated as the change in length divided by the number of days since the previous survey. Surveys include bottom trawl surveys conducted in spring and autumn and scallop dredge surveys conducted each June. TL=total length.

\begin{tabular}{lccccr}
\hline Survey & $\begin{array}{c}\text { Average } \\
\text { survey date }\end{array}$ & $\begin{array}{c}\text { Known } \\
\text { age } \\
\text { (years) }\end{array}$ & $\begin{array}{c}\text { Fractional } \\
\text { age } \\
\text { (years) }\end{array}$ & $\begin{array}{c}\text { Mean } \\
\text { length (SD) } \\
\text { (cm TL) }\end{array}$ & $\begin{array}{c}\text { Growth } \\
\text { increment } \\
\text { (cm TL/d) }\end{array}$ \\
\hline Scallop 2015 & 7-Jun-2015 & 0 & 0.0 & $10.7(1.8)$ & \\
Autumn 2015 & 20-Sep-2015 & 0 & 0.3 & $21.6(3.5)$ & 0.10 \\
Spring 2016 & 1-May-2016 & 1 & 0.9 & $27.2(3.6)$ & 0.03 \\
Scallop 2016 & 29-May-2016 & 1 & 1.0 & $26.2(3.8)$ & -0.04 \\
Autumn 2016 & 27-Sep-2016 & 1 & 1.3 & $36.8(3.7)$ & 0.09 \\
Spring 2017 & 2-Apr-2017 & 2 & 1.8 & $40.9(4.2)$ & 0.02 \\
Scallop 2017 & 11-Jun-2017 & 2 & 2.0 & $41.7(6.2)$ & 0.01 \\
Autumn 2017 & 25-Oct-2017 & 2 & 2.4 & $51.5(6.4)$ & 0.07 \\
Spring 2018 & 7-Apr-2018 & 3 & 2.9 & $50.7(8.1)$ & 0.00 \\
Scallop 2018 & 1-Jun-2018 & 3 & 3.0 & $53.0(6.7)$ & 0.04 \\
Autumn 2018 & 22-Sep-2018 & 3 & 3.3 & $53.0(6.1)$ & 0.00 \\
& & & & & \\
\hline
\end{tabular}




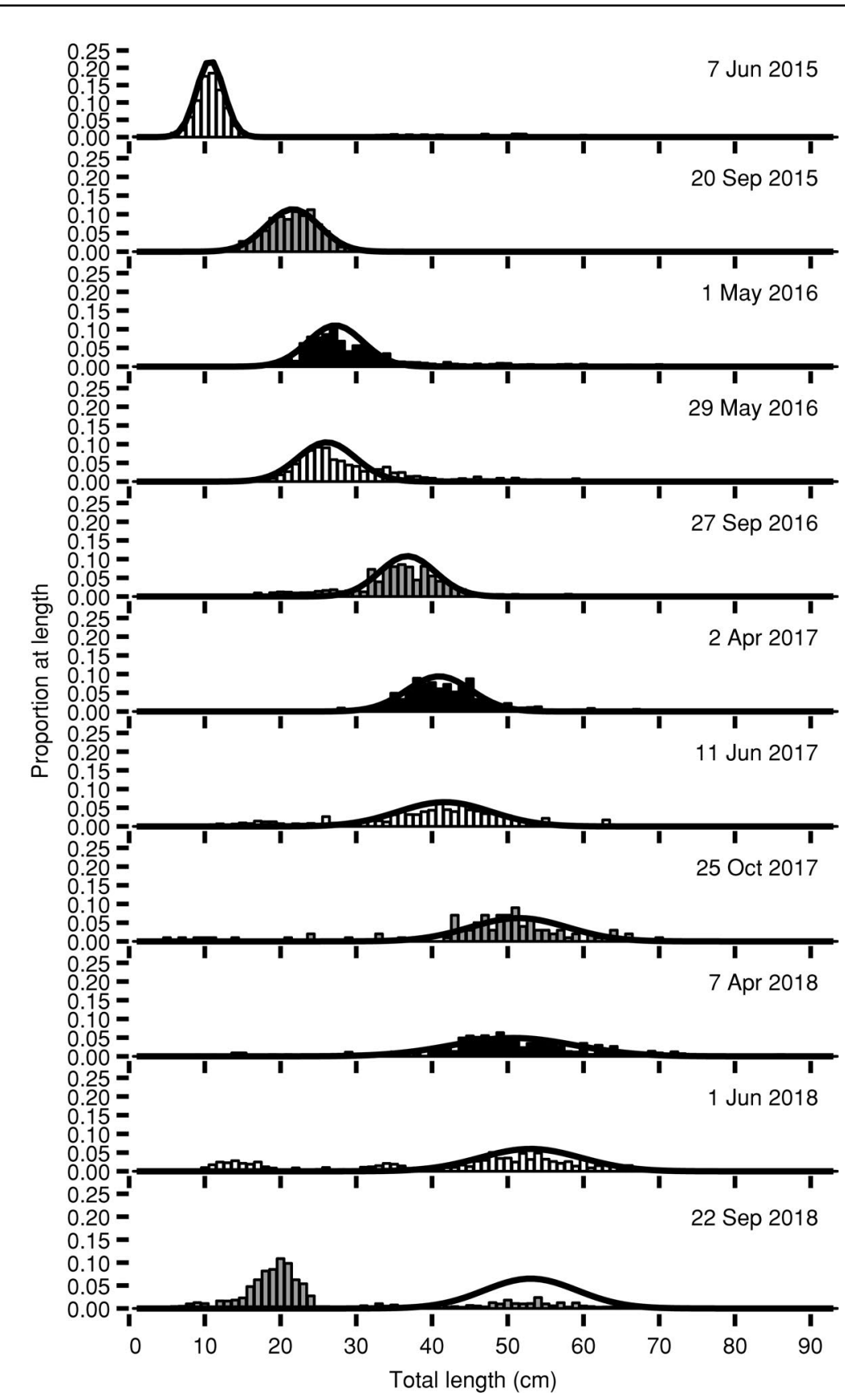

Figure 4

Length-frequency distributions of goosefish (Lophius americanus) from the 2015 year class captured along the Atlantic coast of the United States from Virginia to Georges Bank between June 2015 and September 2018 during scallop dredge (white bars) and autumn (gray bars) and spring (black bars) bottom trawl surveys conducted by the NOAA Northeast Fisheries Science Center. The graphs illustrate the length progression of the 2015 year class. Dates indicate the average date of each survey, and curved lines represent the normal curves that were fit to stratified mean number per tow at length for the year class during each survey. were collected from this length mode as it grew (Table 2, Fig. 1).

Figure 4 shows a new year class entering the population in 2018. This 2018 year class had a modal length of approximately $14 \mathrm{~cm}$ TL in early June and a length of $20 \mathrm{~cm}$ TL by September. These lengths are similar to the lengths of the 2015 year class at age 0 during the same times of year (11 and $22 \mathrm{~cm}$ TL, respectively; Table 1 ).

\section{Hatch date}

Individual counts of daily rings averaged 91.7 and 99.3 for the 2 fish caught on 4 September 2015. There was less than a $5 \%$ difference between the minimum and maximum counts from each fish (ranges: 90-94 rings and 96-101 rings). The estimated hatch dates were 28 May 2015 and 4 June 2015. The average growth rate (from the estimated hatch date until the date of collection) was $1.52 \mathrm{~mm} / \mathrm{d}$ for both fish.

\section{Age estimation}

Ring counts were assigned to 190 illicia and 203 vertebrae (Suppl. Table). Ring counts could not be assigned to 14 illicia because of missing or broken structures (5 fish), processing problems (8 fish), or failure to reach a consensus (1 fish). For readings of vertebrae, no fish were omitted because of processing or aging issues (the spinal column was not collected for one of the fish sampled in September 2015).

Accuracy of ring counts from illicia was $50.0 \%$, with a CV of $20.0 \%$ (number of samples $[n]=190$ ) (Fig. 5A). Where disagreements occurred, the ring count was always higher than the known age. In contrast, accuracy of ring counts from vertebrae had $0 \%$ agreement with the known age and a CV of $69.5 \%(n=203)$ (Fig. 5B). All vertebral ring counts were higher than known ages (98\% exceeded known age by $2-3$ years), with increasing error for higher known ages.

Precision of ring counts from both structures was low. Agreement between repeated readings of illicia was only 8.8\% (CV=44.6\%, $n=57$ ) (Fig. 6A), with a strong bias toward higher counts survey conducted in 2015 (average date: 7 June 2015) and was visible in survey catches through the autumn of 2018. Between September 2015 and April 2018, 204 fish in the test set (Bowker's test: $P<0.001$ ). Agreement between readings from vertebrae was $67.9 \%(\mathrm{CV}=5.9 \%$, $n=56$ ) (Fig. 6B). 


\section{Table 2}

Details for samples of goosefish (Lophius americanus) collected from June 2015 through September 2018 along the Atlantic coast of the United States from Virginia to Georges Bank and used in this study. Sources of samples include surveys of the NOAA Northeast Fisheries Science Center (NEFSC), the NEFSC Study Fleet program, and the NEFSC Fisheries Monitoring Operations Branch (FMOB). SD=standard deviation; TL=total length.

\begin{tabular}{|c|c|c|c|c|c|c|c|}
\hline \multirow[b]{2}{*}{ Year } & \multirow[b]{2}{*}{ Month } & \multirow{2}{*}{$\begin{array}{c}\text { Known } \\
\text { age } \\
\text { (years) }\end{array}$} & \multicolumn{3}{|c|}{ No. of samples } & \multirow{2}{*}{$\begin{array}{c}\text { Total } \\
\text { no. of } \\
\text { samples }\end{array}$} & \multirow{2}{*}{$\begin{array}{c}\text { Mean } \\
\text { length (SD) } \\
(\mathrm{cm} \text { TL })\end{array}$} \\
\hline & & & NEFSC surveys & Study Fleet & FMOB & & \\
\hline 2015 & September & 0 & 2 & & & 2 & $14.5(0.7)$ \\
\hline \multirow[t]{8}{*}{2016} & May & 1 & 3 & & & 3 & 28.0 \\
\hline & June & 1 & 1 & 18 & 36 & 55 & $29.7(3.9)$ \\
\hline & July & 1 & & 11 & & 11 & $33.5(1.9)$ \\
\hline & August & 1 & & 15 & & 15 & $36.7(2.1)$ \\
\hline & September & 1 & 12 & 9 & & 21 & $34.0(2.9)$ \\
\hline & October & 1 & & 11 & & 11 & $36.8(2.3)$ \\
\hline & November & 1 & & 9 & & 9 & $38.6(1.9)$ \\
\hline & December & 1 & & 10 & & 10 & $37.2(1.5)$ \\
\hline \multirow[t]{6}{*}{2017} & January & 2 & & 6 & & 6 & $37.2(0.8)$ \\
\hline & February & 2 & & 13 & & 13 & $37.8(1.6)$ \\
\hline & March & 2 & 6 & & & 6 & $40.3(2.1)$ \\
\hline & April & 2 & 12 & 2 & & 14 & $42.0(2.0)$ \\
\hline & May & 2 & & 5 & & 5 & $44.8(1.9)$ \\
\hline & July & 2 & & 3 & & 3 & $42.7(0.6)$ \\
\hline 2018 & April & 3 & 20 & & & 20 & $51.8(3.6)$ \\
\hline Total & & & 56 & 112 & 36 & 204 & \\
\hline
\end{tabular}

\section{Marginal increment analysis}

A total of 74 illicia were examined in the marginal increment analysis, including 61 illicia that had only one ring inside the edge (ages from $1+$ to 2 years). The narrowest MIR widths were measured in illicia from fish sampled in May-July 2016 and in April 2017; maximum MIR widths were measured in illicia from fish sampled in December 2016 (Fig. 7). Monthly sample sizes ranged from 1 to 12 fish.

Diameters of various marks in illicia were compared against fish length (Fig. 8). The mean diameter of the settlement check was $0.078 \mathrm{~mm}$ (95\% confidence interval [CI]: 0.075-0.081 mm); the diameter of the settling check increased with fish length (linear regression: slope $=0.0005, P=0.04$, coefficient of determination $\left.\left[r^{2}\right]=0.05\right)$. The first ring was visible inside the edge in fish as small as 24-28 cm TL and had a mean diameter of $0.259 \mathrm{~mm}$ (95\% CI: $0.253-0.265 \mathrm{~mm}$ ); the diameter of the first ring increased with fish length (linear regression: slope $=0.0017$, $P=0.0005, r^{2}=0.12$ ). Illicium diameter increased linearly with fish length (linear regression: $r^{2}=0.85$ ).

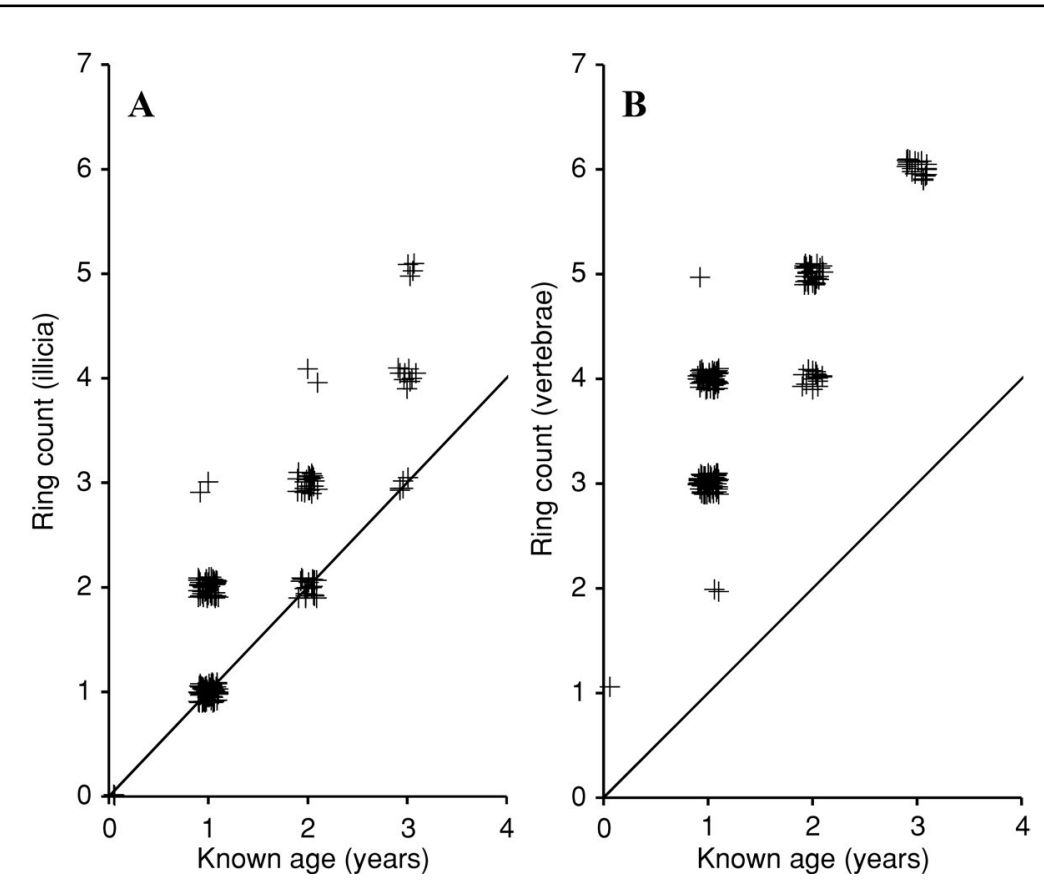

Figure 5

Accuracy of ring counts versus known ages from readings of (A) illicia and (B) vertebrae of goosefish (Lophius americanus) captured along the Atlantic coast from Virginia to Georges Bank between September 2015 and April 2018. The diagonal lines represent equivalence. Points have been jittered to improve the visibility of overlapping data. 

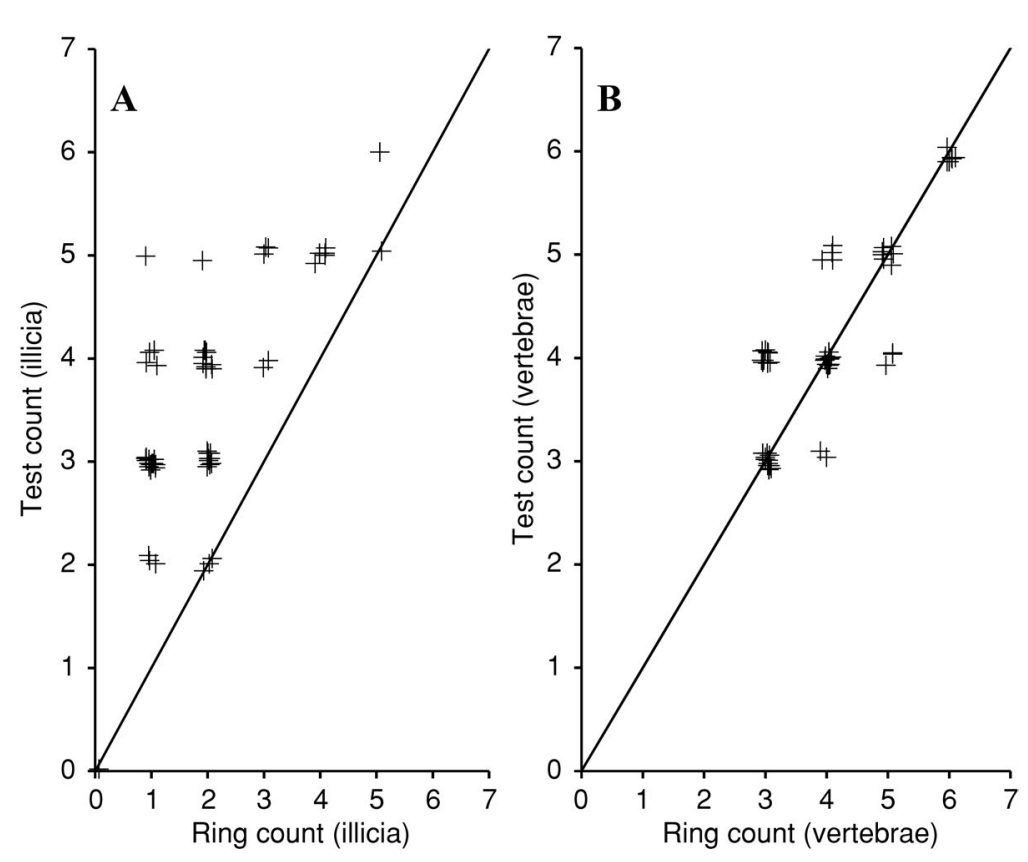

Figure 6

Precision of ring counts, indicated by the relationship between test and original counts from readings of (A) illicia and (B) vertebrae of goosefish (Lophius americanus) captured along the Atlantic coast from Virginia to Georges Bank between September 2015 and April 2018. The diagonal lines represent equivalence. Points have been jittered to improve the visibility of overlapping data. we were not able to validate use of illicia for aging goosefish.

The dominant length mode of the 2015 year class of goosefish was first observed in June 2015 and remained distinct for more than 3 years (Fig. 4). Results from daily aging of 2 fish that were fortuitously collected in the autumn of 2015 confirm that fish in the length mode were members of the 2015 year class. Therefore, we were confident that fish sampled from within this length mode were hatched in 2015 and could be assigned known ages based on this hatch year.

In assigning known ages, we assumed that potential confounding issues (Campana, 2001), such as size-selective mortality, migration, and multiple recruitment events, were not factors in our study. However, all of these issues could have played a role. For example, size-selective mortality could either increase apparent growth rates if the smallest fish are removed by predation or decrease apparent growth rates if the largest, fastest-growing fish are removed through fishing. The 2015 year class had attained exploitable size by June 2017 and was subject to discarding in 2016 (NEFSC, 2020); therefore we may have underestimated size at ages 1-3. The length modes remained distinct, however, and assignment of known age

\section{Growth}

Goosefish in the 2015 year class reached a modal length of $26 \mathrm{~cm}$ TL by the end of their first year of life (in May 2016) (Table 1, Fig. 9) and increased to $42 \mathrm{~cm}$ TL a year later (growth of $16 \mathrm{~cm}$ TL in that year). Growth slowed thereafter, with a modal length of $53 \mathrm{~cm}$ TL at 3 years (growth of $11 \mathrm{~cm}$ TL in the third year). Growth was most rapid between June and September-October.

\section{Discussion}

We used a strong recruitment event as a source of fish with known ages in order to validate the use of 2 aging structures for goosefish. Previous studies (Jónsson ${ }^{7}$; Landa et al., 2013) of white anglerfish have also tracked abundant cohorts across multiple years to test aging methods. Those studies successfully confirmed that the illicium is an appropriate aging structure for white anglerfish; however,

\footnotetext{
${ }^{7}$ Jónsson, E. 2007. Verification of anglerfish (Lophius piscatorius) age estimation through comparison of length modes of age read fish (illicia) to length modes of large year-classes appearing in the Icelandic stock. ICES CM 2007/K:03, 17 p. [Available from website.]
} was unlikely to have been biased by size-selective mortality. Female goosefish can spawn more than once per year ing a bimodal length distribution within a year class. Still, there is no indication of multimodality in the size composition of the age- 0 mode (Fig. 4). Migratory movements may also create checks on an age structure, given that a fish may move between temperature regimes. Goosefish make seasonal inshore-offshore movements (Richards et al., 2008; Rountree et al., 2008), and evidence indicates that some fish make latitudinal movements (Cadrin et al. ${ }^{8}$; Cadrin and $\mathrm{Bank}^{9}$ ). Results from tagging studies of white anglerfish indicate some migrations of very long distances (Laurenson et al., 2005), as well as more frequent seasonal movements (Laurenson et al., 2005; Ofstad, 2013). We were unable to evaluate the potential effects of migration on our results.

\footnotetext{
${ }^{8}$ Cadrin S. X, C. Bank, J. H. Grabowski, and G. Sherwood. 2017. Archival tagging and age validation in the mid-Atlantic, $51 \mathrm{p}$. 2014 monkfish RSA. Project completion report. NOAA grant no. NA14NMF4540227. Northeast Fish. Sci. Cent., Natl. Mar. Fish. Serv., Woods Hole, MA. [Available from website.]

${ }^{9}$ Cadrin, S., and C. Bank. 2019. Estimating growth and movement of juvenile monkfish, 18 p. Final project report. Award no. NA16NMF4540108. Northeast Fish. Sci. Cent., Natl. Mar. Fish. Serv., Woods Hole, MA. [Available from website.]
} (Johnson et al., 2008; McBride et al., 2017), possibly creat- 


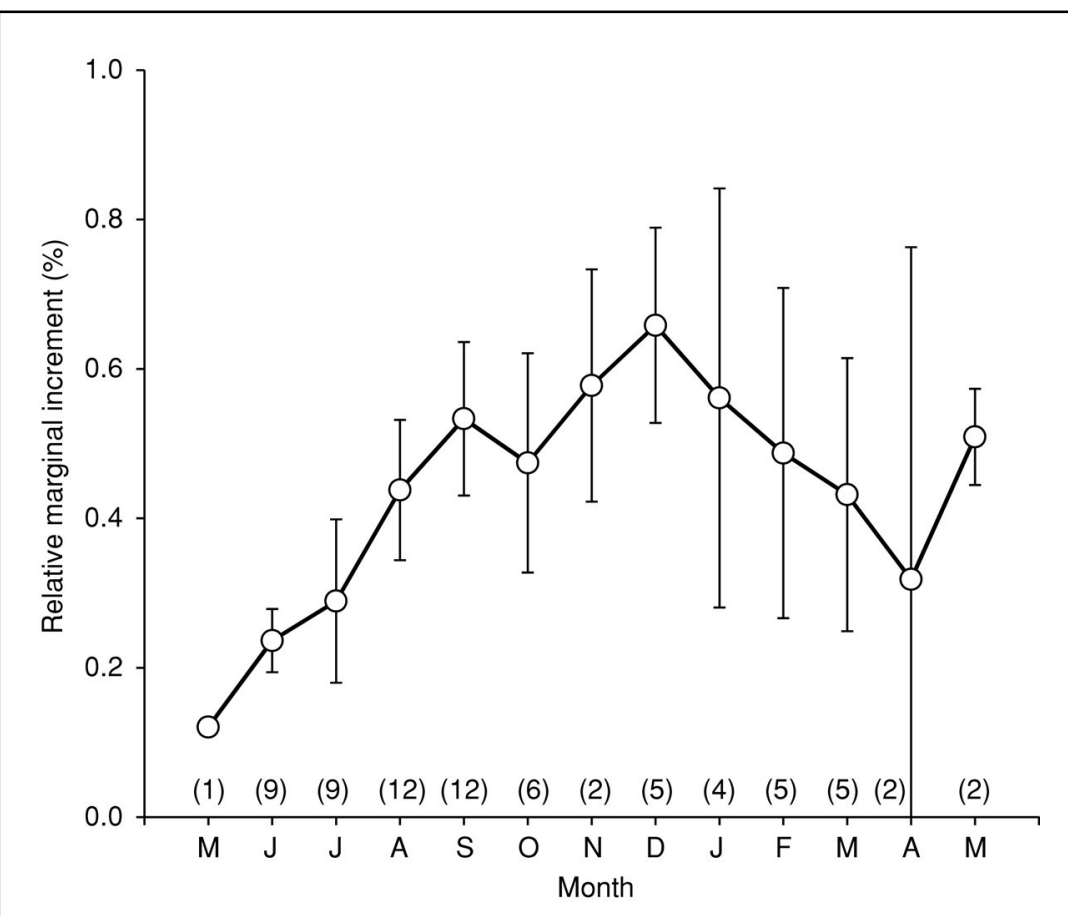

Figure 7

Average relative marginal increment on illicia by month for goosefish (Lophius americanus) captured along the Atlantic coast from Virginia to Georges Bank during May 2016-May 2017. Numerals in parentheses along the $x$-axis indicate monthly number of samples. Error bars indicate $95 \%$ confidence intervals.

\section{Hatch date}

The average hatch date, 1 June 2015 , supports our assumption that fish in the strong length mode were hatched in 2015. This spawning date is consistent with other survey observations and studies of goosefish biology. The strong 2015 recruitment was first observed in the scallop dredge survey conducted in early June 2015 (Fig. 4) but was not observed in the NEFSC bottom trawl survey that took place about 2 months earlier in the same region. This finding indicates that settlement occurred sometime between early April and early June. The similarity between the lengths of the modes representing the 2015 and 2018 year classes in June and September of those years implies that the 2015 year class was growing in a typical way. Able et al. (2007) observed that goosefish settle to the benthos at lengths of about $7 \mathrm{~cm}$ TL (range: $5-8 \mathrm{~cm} \mathrm{TL}$ ), a size that approximates the lower bound of the length mode we observed in June 2015 (Fig. 4).

Results of additional studies of goosefish biology also support our interpretation that the strong length mode was composed of fish hatched in 2015. Goosefish along the Atlantic coast of the United States from Virginia to Georges Bank spawn from late winter through summer (Johnson et al., 2008; McBride et al., 2017). Hatching occurs from June through October with a peak in July (Able et al., 2007), larval abundance peaks in May-June
(Able et al., 2007; McBride et al., 2017), and juveniles settle to the benthos 5-10 weeks after hatching (Able et al., 2007). Therefore, although our sample size for estimating hatch date was small, our results are consistent with expectations from many additional lines of evidence.

\section{Age estimation}

Illicium diameter increased with fish length (Fig. 8), indicating that this structure continues to accrete, one of the characteristics of a structure that is effective for age determination (Van Oosten, 1928). The diameters of both the settlement check and the first ring point to a weak positive relationship with fish length, indicating that the internal portions of the illicium may have changed as the fish grew or that the marks may not have been identified consistently. However, in our study, this change was minimal, as there was little variation in these diameters across all the samples, and the values were similar to those obtained from larger fish (>50 cm TL) (Bank et al., 2020). Ofstad et al. (2013) also noted changes in the size of the first ring in samples of fish under $50 \mathrm{~cm}$ TL.

Bank et al. (2020) suggested that the illicium might prove to be a useful structure for aging of goosefish because they had greater success with illicia than with vertebrae in finding the winter increments after the chemical mark. They also described how recent advances in preparation and interpretation of illicia may have made age interpretation easier for this structure. However, we did not find the expected number of rings on illicia in $50 \%$ of samples (Fig. 5A), and precision was only $9 \%$ (Fig. 6A). These levels of accuracy and precision are not adequate for age estimation. Ring counts from illicia tend to overestimate age. The bias is not consistent, precluding use of a standard correction.

Although studies on other Lophius species have been able to validate yearly marks on illicia (Jónsson ${ }^{7}$; Landa et al., 2013), the structure remains a challenge to read (Duarte et al. ${ }^{1}$; Landa et al., 2013). Many rings are visible, and it is difficult to choose which ones to count. Unlike with typical aging structures, the spacing between annuli does not decrease with age and is consistent across the section; increment width may even increase near the edge (Duarte et al. ${ }^{1}$ ). Disagreements between otolith- and illicium-derived ages of white anglerfish were not resolved until Wright et al. (2002) showed that an additional ring (i.e., false annulus) is formed on illicia. However, it is possible that goosefish illicia may have multiple false annuli. This complexity in reading illicia may also account for the 


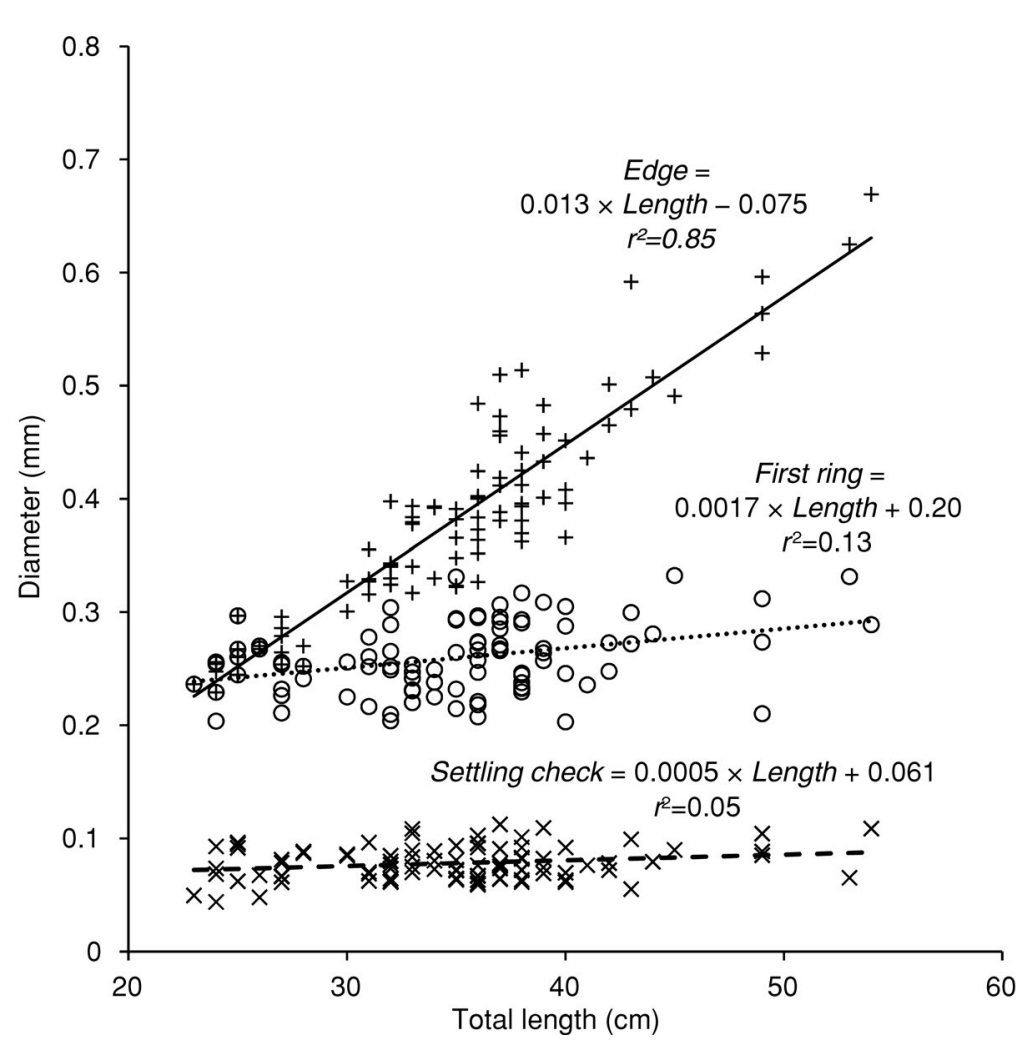

Figure 8

Relationships between the diameters of marks on illicia and total lengths of goosefish (Lophius americanus) captured along the Atlantic coast from Virginia to Georges Bank from May 2015 through July 2017. Multiplication signs, circles, and crosses indicate values for diameters of settling checks, first rings, and edges of illicia, respectively. For each type of mark, trend lines, linear regression equations, and coefficients of correlation $\left(r^{2}\right)$ are shown.

from vertebrae also occurred for the 2 smallest fish in the study by Bank et al. (2020). Possible reasons for the overestimation of vertebral ages include checks due to sporadic feeding behavior, variation in short-term growth rates, and variation in temperature as the fish migrate vertically (Bank et al., 2020). In our study, precision of vertebral ring counts was below acceptable levels but was much higher than ring counts from illicia. The differing levels of precision may have been because of the age reader's greater level of experience with vertebrae than with illicia or because of the false annuli and multiple checks seen in illicia.

\section{Marginal increment analysis}

Results from marginal increment analysis (Fig. 7) provide evidence of annual formation of rings on the illicium. However, the analysis was not conclusive as a result of low sample sizes, high variability, and a short time span (13 months). This analysis included only fish of ages from $1+$ to 2+ years; therefore, these results should not be applied to older age classes.

We followed Campana's (2001) guidelines for implementing marginal increment analysis as much as was feasible: we made an effort to view samples in random order and examined only one year class. Our sampling did not extend for 2 years, as recommended, and use of

low precision of readings of illicia in our study. Other relevant factors may be the age reader's limited experience with the structure and possible differences in lighting between the 2 readings. The age reader did not identify the same rings and may have picked a different position for the first ring each time. However, the reader was careful to avoid counting a false annulus, as is seen in other Lophius species. This false annulus was identified in 14 of the 22 images of illicia from goosefish annotated by J. Landa (Landa ${ }^{5}$ ).

Recommendations for reading illicia of other Lophius species (Duarte et al. $\left.{ }^{1}\right)$ include starting with larger $(>50 \mathrm{~cm}$ TL) fish and adjusting the lighting and focus as each sample is viewed. The fish in this study were mainly smaller than $50 \mathrm{~cm}$ TL, precluding the first suggestion, although the samples used by Bank et al. (2020) were mainly over $50 \mathrm{~cm}$ TL. The age reader in our study adjusted the microscope while viewing samples; however, it was impossible to do so during training on images.

The age reader's vertebral ring counts never agreed with known ages and were always higher than the known age (often by 2-3 years). Overestimation of ages derived larger sample sizes may have revealed a cyclic pattern. However, our results provide a provisional estimate of the timing of ring formation.

\section{Growth}

Growth rates estimated from modal length progression of the 2015 year class (11-16 cm TL/year; Table 1) were much faster than estimates based on readings of vertebrae or illicia in our study (Fig. 9). Our illicium-derived growth estimates (7-10 cm TL/year) were slightly faster than our vertebra-derived estimates $(5-10 \mathrm{~cm}$ TL/year). The vertebral estimates were similar to those from earlier studies in which vertebrae were used (6-10 cm TL/year; Richards et al., 2008), indicating that the aging method was applied similarly in the 2 time frames and that the 2015 year class grew normally.

Our estimate of growth in the first few months of life $(1.52 \mathrm{~mm} / \mathrm{d})$ is comparable to the rates of $1.4 \mathrm{~mm} / \mathrm{d}$ (pelagic) and $1.3 \mathrm{~mm} / \mathrm{d}$ (benthic) for young-of-the-year fish found by Able et al. (2007), who had a larger sample size $(n=60)$ than that of our study. However, our observations of 


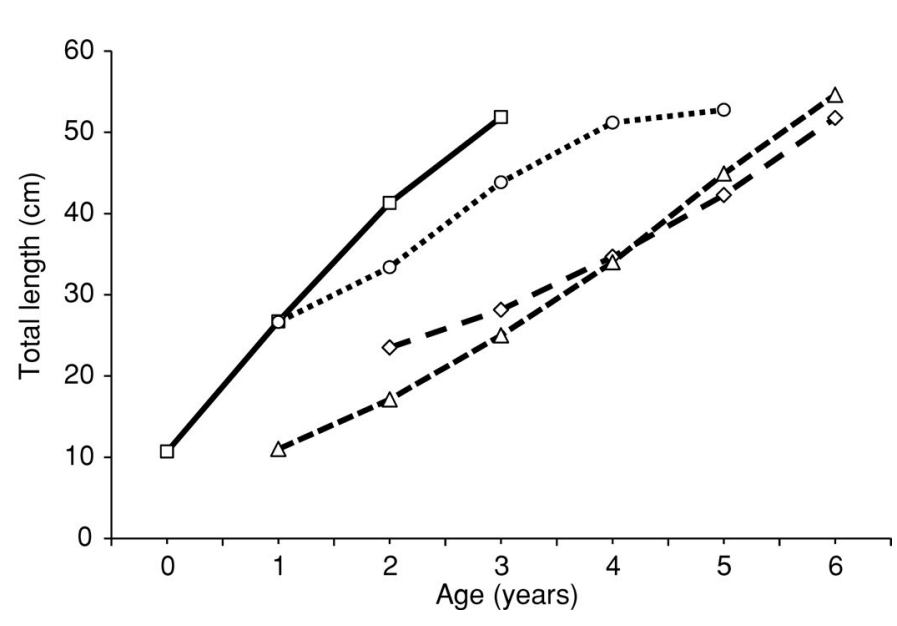

Figure 9

Mean lengths at age of goosefish (Lophius americanus) captured in the spring along the Atlantic coast from Virginia to Georges Bank, as estimated from 4 sources: modal analysis of length frequencies of fish from the 2015 year class caught in surveys during 2015-2018 (squares), readings of illicia from fish captured for this study (circles), readings of vertebrae from fish captured for this study (diamonds), and readings of vertebrae from historical data in Richards et al. (2008) (triangles).

than previously thought. This finding has implications for our understanding of productivity in this species. Previous measurements of the length at which $50 \%$ of fish reach sexual maturity are $38 \mathrm{~cm}$ TL in males and $44 \mathrm{~cm}$ TL in females (Richards et al., 2008). Age estimates associated with these lengths are 4.3 years for males and 4.9 years for females (Richards et al., 2008). Results of our study indicate that goosefish instead reach the median length at maturity in their first 2 years. Similarly, the minimum legal size in the fishery ( $43 \mathrm{~cm}$ TL), previously thought to correspond to ages 4-5 (Richards et al., 2008), would instead correspond to age 2 under our current understanding. More research, and an effective method for estimating ages, will be needed to develop a full growth curve.

\section{Conclusions}

Results of our validation study indicate that ages cannot be estimated from either illicia or vertebrae of goosefish at present. Although results of the marginal increment analysis indicate that a ring is laid down on the illicium in spring-summer, age estimates from both illicia and vertebrae had insufficient levels of accuracy and precision

young-of-the-year fish attaining lengths of $10 \mathrm{~cm}$ TL shortly after settlement conflict with the conclusion by Able et al. (2007) that the first annulus is laid down at an average length of $9.6 \mathrm{~cm}$ TL. A settlement check or false annulus may have been misinterpreted as an annulus in the Able et al. (2007) study.

In a number of Lophius species, growth curves derived from age estimates from vertebrae, illicia, or otoliths have been approximately linear with little evidence of slowing with age (Fariña et al., 2008; Maguire et al., 2008). However, past results for white anglerfish indicate that too many rings may be counted and that growth may be underestimated, particularly among young fish ( $\leq 3$ years) (Velasco et al., 2008). Our results indicate a similar pattern of underestimation of size at age up through age 3 in goosefish. Faster growth at earlier ages would be expected to result in a curvilinear growth curve, as is typical of most fish species, even if size at age for older fish was essentially linear.

Our revised understanding of the growth of goosefish in the first few years of life brings it more in line with knowledge of the growth of a congener in Europe, the white anglerfish, which reaches about $40 \mathrm{~cm}$ TL by age 2 (Jónsson ${ }^{7}$ ). This size closely matches the $42 \mathrm{~cm}$ TL modal length we observed in our study for goosefish at age 2 (in June 2017). Maximum observed size is comparable between the 2 species, given that the maximum observed size is $138 \mathrm{~cm}$ TL for goosefish (Richards et al., 2008) and 125-142 cm for white anglerfish (Jónsson ${ }^{7}$; Landa et al., 2013; Ofstad et al., 2013).

The observed growth rate, based on the progression of the length mode for goosefish at ages $0-3$, is faster to be used for age estimation.

Despite this outcome, important observations were made about growth rates in goosefish. Size at age 3 was nearly double previous estimates from vertebral aging, indicating that the species has higher productivity than has previously been thought.

It remains important to find a valid aging method for this species so that growth rates can be modeled and the population can be managed more effectively. Other structures, such as the operculum or other bones (Elzey et al., 2015), may be worth investigating. Other future efforts could include microchemical analysis (Siskey et al., 2016) or staining (Natanson et al., 2007), which could help in identifying annuli in illicia or vertebrae. In-person training to learn methods for reading illicia from experienced personnel in Europe may also help with reading illicia of goosefish.

\section{Acknowledgments}

We would like to extend our appreciation to A. Linares, A. Jones, and M. Durst-Scarlett for help with dissections and preparation of samples. Thank you to P. Hasslund for preparing and imaging the lapillar otoliths and to D. Secor for training the first author in these methods. A. Miller and C. Tholke assisted with generating the figures. We also are grateful to the staff of the NEFSC Ecosystems Surveys Branch, the crews and staff of the Study Fleet program, and the fishery monitors for collecting samples and to the anonymous reviewers for their insightful comments. 


\section{Literature cited}

Able, K. W., P. J. Clarke, and D. A. Witting.

2007. Transitions in the morphological features, habitat use, and diet of young-of-the-year goosefish (Lophius americanus). Fish. Bull. 105:457-469.

Armstrong, M. P., J. A. Musick, and J. A. Colvocoresses.

1992. Age, growth, and reproduction of the goosefish Lophius americanus (Pisces:Lophiiformes). Fish. Bull. 90:217-230.

Bank, C. M., K. Oliveira, S. J. Sutherland, M. P. Armstrong,

J. Landa, and S. X. Cadrin.

2020. Age validation of goosefish (Lophius americanus) in the northeastern United States. Fish. Bull. 118:8-20. Crossref

Bowker, A. H.

1948. A test for symmetry in contingency tables. J. Am. Stat. Assoc. 43:572-574. Crossref

Campana, S. E.

2001. Accuracy, precision and quality control in age determination, including a review of the use and abuse of age validation methods. J. Fish Biol. 59:197-242. Crossref

Chang, W. Y. B.

1982. A statistical method for evaluating the reproducibility of age determination. Can. J. Fish. Aquat. Sci. 39:1208-1210. Crossref

Elzey, S. P., K. A. Rogers, and K. J. Trull.

2015. Comparison of 4 aging structures in the American shad (Alosa sapidissima). Fish. Bull. 113:47-54. Crossref

Fariña, A. C., M. Azevedo, J. Landa, R. Duarte, P. Sampedro, G. Costas, M. A. Torres, and L. Cañás.

2008. Lophius in the world: a synthesis on the common features and life strategies. ICES J. Mar. Sci. 65:1272-1280. Crossref

Gayanilo, F. C., Jr., P. Sparre, and D. Pauly.

2005. FAO-ICLARM stock assessment tools II (FiSAT II). Revised version. User's guide. FAO Comput. Inf. Ser. (Fish.) 8, 168 p. FAO, Rome.

Haring, P., and J.-J. Maguire.

2008. The monkfish fishery and its management in the northeastern USA. ICES J. Mar. Sci. 65:1370-1379. Crossref

Hartley, D.-L. R.

1995. The population biology of the goosefish, Lophius americanus, in the Gulf of Maine. M.S. thesis, 142 p. Univ. Mass, Amherst, MA.

Hernández, C., J. Landa, J. Barrado, A. Antolínez, and M. B. Santos.

2015. First estimates of age and growth of juvenile black anglerfish (Lophius budegassa), in north-eastern Atlantic waters. Fish. Res. 161:269-272. Crossref

Hislop, J. R. G., A. Gallego, M. R. Heath, F. M. Kennedy,

S. A. Reeves, and P. J. Wright.

2001. A synthesis of the early life history of the anglerfish, Lophius piscatorius (Linnaeus, 1758) in northern British waters. ICES J. Mar. Sci. 58:70-86. Crossref

Hoenig, J. M., M. J. Morgan, and C. A. Brown.

1995. Analysing differences between two age determination methods by tests of symmetry. Can. J. Fish. Aquat. Sci. 52:364-368. Crossref

Johnson, A. K., R. A. Richards, D. W. Cullen, and S. J. Sutherland. 2008. Growth, reproduction, and feeding of large monkfish, Lophius americanus. ICES J. Mar. Sci. 65:1306-1315. Crossref

Landa, J., J. Barrado, and F. Velasco.

2013. Age and growth of anglerfish (Lophius piscatorius) on the Porcupine Bank (west of Ireland) based on illicia age estimation. Fish. Res. 137:30-40. Crossref
Laurenson, C. H., A. Johnson, and I. G. Priede.

2005. Movements and growth of monkfish Lophius piscatorius tagged at the Shetland Islands, northeastern Atlantic. Fish. Res. 71:185-195. Crossref

Maguire, J.-J., P. Pereda, R. Duarte, H. Dobby, and M. Azevedo. 2008. Monkfish/anglerfish across the world; common problems and common solutions: an introduction to papers presented at the ICES theme session in September 2007. ICES J. Mar. Sci. 65:1270-1271. Crossref

McBride, R. S., A. K. Johnson, E. K. Lindsay, H. J. Walsh, and R. A. Richards.

2017. Goosefish Lophius americanus fecundity and spawning frequency, with implications for population reproductive potential. J. Fish Biol. 90:1861-1882. Crossref

Natanson, L. J., J. A. Sulikowski, J. R. Kneebone, and P. C. Tsang. 2007. Age and growth estimates for the smooth skate, Malacoraja senta, in the Gulf of Maine. Environ. Biol. Fishes 80:293-308. Crossref

NDPSWG (Northeast Data Poor Stocks Working Group). 2007. Monkfish assessment report for 2007. Northeast Fish. Sci. Cent. Ref. Doc. 07-21, 232 p. [Available from website.]

NEFSC (Northeast Fisheries Science Center).

2010. 50th northeast regional stock assessment workshop (50th SAW): assessment report. Northeast Fish. Sci. Cent. Ref. Doc. 10-17, 844 p. [Available from website.]

2020. Operational assessment of the black sea bass, scup, bluefish, and monkfish stocks, updated through 2018. Northeast Fish. Sci. Cent. Ref. Doc. 20-01, 160 p. [Available from website.]

Ofstad, L. H.

2013. Anglerfish Lophius piscatorius L. in Faroese waters: life history, ecological importance and stock status. Ph.D. diss., 23 p. Univ. Troms $\varnothing$, Troms $\varnothing$, Norway. [Available from website.]

Ofstad, L. H., C. Angus, T. Pedersen, and P. Steingrund.

2013. Age and growth of anglerfish (Lophius piscatorius) in Faroese waters. Fish. Res. 139:51-60. Crossref

Palmer, M. C., S. E. Wigley, J. J. Hoey, and J. E. Palmer.

2007. An evaluation of the Northeast Region's Study Fleet pilot program and electronic logbook system: phases I and II. NOAA Tech. Memo. NMFS-NE-204, 78 p.

Pauly, D., N. David, and J. Hertel-Wulff.

1986. Fishery statistics on the microcomputer: a BASIC version of Hasselblad's NORMSEP program. Bay Bengal Progr., BOBP/Mag/3, 12 p. Bay Bengal Progr., Colombo, Sri Lanka. [Available from website.]

Penttila, J., and L. M. Dery (eds.).

1988. Age determination methods for northwest Atlantic species. NOAA Tech. Rep. NMFS-72, 135 p.

Richards, R. A.

2016. 2016 monkfish operational assessment. Northeast Fish. Sci. Cent. Ref. Doc. 16-09, 109 p. [Available from website.]

Richards, R. A., P. C. Nitschke, and K. A. Sosebee.

2008. Population biology of monkfish Lophius americanus. ICES J. Mar. Sci. 65:1291-1305. Crossref

Richards, R. A., J. Moser, B. Dunnigan, and L. A. Alade.

2011. Archival tagging methods for monkfish. Trans. Am. Fish. Soc. 140:582-586. Crossref

Rountree, R. A., J. P. Gröger, and D. Martins.

2008. Large vertical movements by a goosefish, Lophius americanus, suggests the potential of data storage tags for behavioral studies of benthic fishes. Mar. Freshw. Behav. Physiol. 41:73-78. Crossref

Schneider, C. A., W. S. Rasband, and K. W. Eliceiri.

2012. NIH Image to ImageJ: 25 years of image analysis. Nat. Methods 9:671-675. Crossref 
Secor, D. H., J. M. Dean, and E. H. Laban.

1991. Manual for otolith removal and preparation for microstructural examination, 55 p. Electric Power Res. Inst., Palo Alto, CA, and Belle W. Baruch Inst. Mar. Biol. Coast. Res., Univ. South Carolina, Columbia, SC.

Siskey, M. R., V. Lyubchich, D. Liang, P. M. Piccoli, and D. H. Secor. 2016. Periodicity of strontium: calcium across annuli further validates otolith-ageing for Atlantic bluefin tuna (Thunnus thynnus). Fish. Res. 177:13-17. Crossref

Stauffer, G. (compiler).

2004. NOAA protocols for groundfish bottom trawl surveys of the nation's fishery resources. NOAA Tech. Memo. NMFS-F/SPO-65, $205 \mathrm{p}$.

Sun, C.-L., S.-P. Wang, and S.-Z. Yeh.

2002. Age and growth of the swordfish (Xiphias gladius L.) in the waters around Taiwan determined from anal-fin rays. Fish. Bull. 100:822-835.

TWG (TWAIN Working Group).

2008. TWAIN specification, vers. 2.0. TWAIN Working Group, Raleigh, NC. [Available from website, accessed August 2015.]
Van Oosten, J.

1928. Life history of the lake herring (Leucichthys artedi, Le Seur) of Lake Huron as revealed by its scales, with a critique of the scale method. Fish. Bull. 44:265-428.

Velasco, F., J. Landa, J. Barrado, and M. Blanco.

2008. Distribution, abundance, and growth of anglerfish (Lophius piscatorius) on the Porcupine Bank (west of Ireland). ICES J. Mar. Sci. 65:1316-1325. Crossref

Vilizzi, L., and K. F. Walker.

1999. Age and growth of the common carp, Cyprinus carpio, in the River Murray, Australia: validation, consistency of age interpretation, and growth models. Environ. Biol. Fishes 54:77-106. Crossref

Wright, P. J., D. A. Woodroffe, F. M. Gibb, and J. D. M. Gordon. 2002. Verification of first annulus formation in the illicia and otoliths of white anglerfish, Lophius piscatorius using otolith microstructure. ICES J. Mar. Sci. 59:587593. Crossref 